\title{
Nursery observation in the training of child psychiatry registrars
}

\author{
Alicia Etchegoyen and Joanne Stubley
}

\begin{abstract}
Thls paper discusses a training opportunity based on an adcplation of the Infiant Observation method. This is a much shorter moctule, of ten weokly vistts.

We describe three training components: (a) an opportunity to leam directly about child development and to become famlliar with chlldren's verbol and nonverbal communications; (b) a direct experience of the emotional impact and strenoth of primitive feelings, both in the children and in the trainees themselves, and (c) leaming to be a 'non-particlpant' observer. We belleve that the cbillty to observe without intervention is extremely importont in the development of clinical skills. We suggest that this is the comerstone of the method and that it may have a wider application to the training of those in the caring professions, including poychicitists, nurses and soctal workers.
\end{abstract}

In this paper we discuss a training opportunity in nursery observations provided for registrars in child psychiatry undergoing general training at the Riverside Mental Health Trust. The Riverside experfence is an adaptation of the Infant $\mathrm{Ob}$ servation method. This was originally developed at the Tavistock Clinic for the training of child psychotherapists. It consists of a regular weekly observation of a mother and baby, in their natural setting, for 1-2 years.

This training module aims to preserve the essentials of the method but uses a much shorter time span in a different setting. The trainee is expected to visit for around an hour each week over a period of 10 weeks. A detailed account of what happened, written after each visit, is discussed with a supervisor and peer group. Miller et al (1989) summarise the observation as "learning about early emotional development ... and also learning from one's own response to the observations".

The learning components of the Infant Observation method

Opportunity to learn about child development

Observation of a young child offers the opportunity to learn directly about child development and to become familiar with children's verbal and non-verbal communications with each other and with adults.

This is the time when the child begins to move into the wider world, facing periods of brief separation from significant figures. The child starts to make friends and to join in group activities. He is intensely curious about the world and deeply interested in relationships, primarily with the adults in his life. Usually at this age, the child has developed a 'secure base', a loving relationship with the mother. This one-to-one relationship is often affected by the arrival of a new baby. The child has to learn to share mother with others, including the father.

The re-negotiation of primary relationships and moving away from the family go hand in hand with the child acquiring a sense of being separate from his parents. A young child comes to the nursery knowing who he is and with some confidence to master the environment.

Anna Freud (1979) suggests that the young child's "adaptation to the nursery represents the end product of significant developmental lines"; for example from dependence to emotional selfreliance, from egocentricity to objectivity, from play to work, from irresponsibility to responsibility for bodily management.

These developmental gains are not, however. stable. The young child struggles between 'grown up' and baby like states. The developmental perspective thus helps the trainee to recognise and appreciate how infantile patterns of behaviour may persist or get worked through, along the separation-individuation continuum.

By looking at the ordinary interactions in the nursery setting, focusing closely on the process, the trainee gets a fairly good idea about the intensity and complexity of the child's emotional development. The learning that takes place is about the emotional interactions between the child, his peer group and the adults, including how patterns of peer relationships grow and develop and how the child manages the experience of separation on arrival and departure. 


\section{Direct experience of feelings}

The trainee is exposed, probably for the first time, to a direct experience of the emotional impact and strength of primitive feelings, both in the children and in themselves, particularly the child's pain and anxiety.

\section{Learning to be a 'non-participant' observer}

To assume the role of a 'non-participant' observer, that is to acquire the ability to observe without intervention, is extremely important in the development of clinical skills. We believe this to be the fundamental training aspect of the method which presents particular challenges.

The observer has to negotiate an 'emotional place' in the nursery. He is to be friendly but not too close, receptive and not intrusive or judgmental. He has to gain some awareness of his conscious and unconscious attitudes towards the observation. The emotional impact on the observer is often profound and sometimes disturbing.

Deprived of the active professional role, he has to struggle to keep his sense of self in the emotionally charged field of the group relationships. The observer has to manage uncertainty and a large measure of helplessness. Areas of personal vulnerability may be stirred up by the emotional impact of the observation.

The crux of the matter is to remain receptive to the emotional experience of the observation, to reflect and to make sense of it without enacting a role or taking the initiative. This process of containment (Bion, 1962) is greatly helped by the supervision group, where the conscious and unconscious aspects of the experience can be processed and conceptualised.

The seminar is invaluable to help the student to appreciate the manifestations of the transference and countertransference in the observation situation. Not uncommonly, the observer will feel pulled in different directions, for example other children may look to him for attention, the nursery staff may see him as an expert to provide advice or reassurance or just as another "pair of hands'. The observer may inadvertently be drawn to identify with the unmet needs of the observed child or a staff member, becoming judgmental, upset or withdrawn when the emotional intensity is too much to bear. The complexity and power of the identifications within himself and the members of the nursery become apparent.

Sharing experiences with others of the group helps the trainee to tolerate and distinguish the source and type of anxiety: those stirred up by being in the new role of observer, those which are encountered by the child adjusting to the new environment, and those which arise from the revival of conflictual infantile feelings in the observer or other adults in the nursery.

\section{The Riverside experience}

The process begins with contacting the nursery and arranging an initial meeting to explain what is required and elicit support in the proceedings. The nursery staff, if willing, are then asked to choose a suitable child, gain parental consent and help set the regular time for the observation. The staff are asked to select a child with no particular problems identified and of an intact family, if possible, so as to keep the observation close to the norm. The nursery staff are informed of the purpose of the observation, in that it is the process that is important, and therefore the observer is only there to observe and not to be a part of the nursery. They introduce the observer to the children but, to make the observation as normal as possible, they do not say what the purpose of the visits is, or single out the observed child in any way. If possible, the observations take place at a time when the children are involved in unstructured play.

Process notes are written as soon as possible following the observation. These are taken to the supervision groups held weekly with a child psychotherapist.

\section{The trainee's perspective}

The nursery observation afforded me a unique opportunity in my training to explore issues basic to both child psychiatry and psychotherapeutic principles. As an introductory exercise to working with children, the observation proved invaluable. It provided numerous demonstrations of normal physical, cognitive and emotional development. It also allowed the process of acclimatising to the child's perspective. As the observations continued, I became aware of two major issues. One involving the first hand experience of the role of observer. The second issue was that of the exposure to the intensities and complexities of primitive anxieties. I shall illustrate with a clinical vignette. $S$ is threeyears-old, the third child in a British Bengali family. The nursery staff reported that $S$ was brought to the nursery most frequently by her mother but occasionally by her father. The initial period of separation had been difficult with $S$ crying when her mother left. However, the staff felt that her mother had always handled this in a sensitive and caring manner. The theme separation emerged early in the observations. For $S$, the coming and going in relation to the nursery and to her family appeared a major area of concern. I realised quite quickly that $S$ was very aware of my presence and also my coming and going.

This was the last day of my observation. The previous week $\mathbf{S}$ and her family had been on holiday. $S$ had been brought late to the nursery by her mother who reported that $S$ had been 
unwell the previous night. The staff informed me that $S$ had been very tearful, clinging to her mother and unwilling to let her go. When I arrived, she was outside with several other children. $\mathrm{S}$ was in a pushcar, going around the perimeter of the garden, looking half asleep. She looked up at me from the other side of the playarea, stopped her pushcar and put her hands to her face. I could just hear the quiet sobs of her crying. The urge to comfort her was very strong. The other children continued to play, seemingly unaware, and the nursery nurse was temporarily distracted. Over the next few minutes, I saw her steal a glance through her fingers in my direction several times, while continuing to sob. After some time had elapsed, S got out of the pushcar and walked over to the nurse, no longer crying. She flopped silently onto the nurse's lap, like a rag doll. The nurse responded by affectionately letting her be. A little later $S$ went over to the sandpit. Looking more alert, she picked up a small red bucket and filled it with sand. She then slowly let the sand trickle out until the bucket was empty. This process was repeated a number of times. She then went over to join the other children and was soon back in her pushcar, looking happier.

This excerpt demonstrates some of the difficulties encountered as an observer. Through supervision. I was able to understand the experience in terms of Bion's concept of container-contained. The distress shown by $S$ was projected into me, urging me to act. I felt helpless and wanted to comfort the little girl. I also felt angry that she was crying and not noticed by staff. The echo of her experience of mother leaving that morning was clearly felt. It seemed this also followed the theme of separation with the break in observation the previous week, and the fact that this was to be my last observation. The containment and hence the ending of the distress, may be viewed in terms of my ability to hold this distress and anger, and not be pushed into action. The urge to act was precipitated by the desire to wipe out the unpleasant experience of pain and helplessness in the child and in myself. This desire to act, to erase pain and helplessness perpetuates the belief in one's ability to be the omnipotent healer. Remaining in the reflective mental space allowed by the observation experience, I believe my inaction provided the child with an opportunity for growth, to find her own solution to autonomy, by symbolising the comings and goings through play. It also gave me an opportunity to assess the resources that $S$ possessed to master the situation.

It was also an important learning experience for me, to become aware of my own difficulties in saying goodbye which closely replicated that of the little girl. Leaving one's patients to move on to another training job is part of the life of junior doctors. Through the nursery observation. I gained first hand experience of why junior (and sometimes senior) doctors often 'act the problem out' by leaving it to the last minute to tell their patients that they will be leaving the job. The experience helped to bridge the gap between an intellectual knowledge and the emotional understanding of these situations.

The ability to resist this push to act, to be able to reflect, in the face of powerful emotions was a clinical skill slowly learned but one which proved vital in a number of cases. The knowledge that this experience imparted could then be generalised to individual patient care, working with families and within the wider system network.

To evaluate the experience of the nursery observation for other trainees, we sent a questionnaire to the previous seven child psychiatry registrars for the last four years. Six trainees responded, with virtually unanimous results. All trainees reported that they had found the outcome of the module to be both a good introductory experience and capable of changing their experience of working with children.

No major practical difficulties in setting up the observation were described. The acquisition of clinical skills reported by trainees, early on in the job placement, seemed to justify the time spent and enlisted consultant's cooperation.

Five of the six found the nursery observation a source of both personal and professional growth, the other trainee focused on the personal experience. All reported it as helpful.

\section{Conclusion}

The nursery observation module is a valuable training experience for registrars in child psychiatry. It offers an opportunity to develop therapeutic skills which can be generalised to various aspects of patient management.

In our opinion the Riverside experience has proven to be a time-effective adaptation of the lengthier Infant Observation. Learning to 'observe without preconceptions', tolerating anxiety and uncertainty has remained as the core training experience and has been highly appreciated by the trainees. We see the Riverside experience as a solid base from which trainees may then broaden their understanding and experience of psychotherapy.

We think that this training opportunity is relevant not only to the training of child psychiatrists but also to adult psychiatrists (and other professionals). The recent Royal College guidelines for training in general psychiatry (1993) make psychotherapy training mandatory. This module could be usefully incorporated as an introductory experience to 
psychotherapy and hence would make a positive contribution towards implementing the guidelines.

Furthermore we suggest that the observation method may have a wider application to the training of those in the caring professions, including general psychiatrists, nurses, and social workers. It is generally agreed that experiential learning to gain some understanding and awareness of personal and interpersonal attitudes is beneficial. To this end sensitivity groups are often used for training. We suggest that learning to become a receptive, non-participant observer, able to reflect on the emotional experience of the encounter, adds a different dimension to that of the 'here and now' interpersonal situation of the sensitivity groups. What is developed is the capacity for self-observation as a professional tool. This has been found to be a skill that enhances clinical effectiveness and fosters professional development (Trowell \& Rustin, 1991).

\section{References}

BION. W. R. (1962) A theory of thinking. International Journal of Psychoanalysis, 33, 306-310.

FREuD, A (1979) The nursery school from the psychoanalytic point of view. In The Writings of Anna Freud, Vol VIII, pp. 315-330.

MiLler, L., Rustin, M., RUSTIN, M., et al (1989) Closely Observed Infants. London: Duckworth

The Royal College OF PSYChiatrists (1993) Guidelines for psychotherapy training as part of general professional psychiatric training. Psychiatric Bulletin, 19, 695-698.

TROWEL., J. \& RusTiN, M. (1991) Developing the internal observer in professionals in training. Infant Mental Health Journal, 1, 233-245.

*Alicia Etchegoyen, Consultant Child Psychiatrist, Chelsea and Westminster Hospital, London; and Joanne Stubley, Senior Registrar in Psychotherapy, St Anne's Hospital, Tavistock Rotation

*Correspondence

\section{The Royal College of Psychiatrists' Journal of Continuing Professional Development}

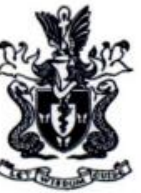

Subscription rate for Volume 3, 1997

(8 issues starting January):

Europe, including UK $£ 70.00$

USA US $\$ 110.00$ Elsewhere $€ 70.00$

Full airmail $£ 6 / \$ 10$ extra

$A P T$ with CPD registration $£ 85.00$

To enter your subscription or to obtain a sample copy of APT, contact: Publications Subscription Department, Royal Society of Medicine Press Limited, PO Box 9002, London W1M 0ZA, UK. Tel: +44(0)171 290 2927/8; Fax: +44(0)171 2902929

College members wishing to receive APT and register for $C P D$ should contact the Registration Department, Tel: $+44(0) 171$ 2352351 in Psychiatric Treatment

\section{of Continuing Professional Development}

\section{Contents of the March 1997 issue}

Editorial: Importance of CPD for consultant psychiatrists. M Aveline

Practical pharmacotherapy for anxiety.

D Nutt, C Bell

Pharmacotherapy for anxiety disorders: drugs available. P Cowen

Pharmacotherapy for anxiety disorders: using the drugs available. $P$ Tyrer

The provision of assertive treatment services for severely mentally ill patients. $T$ Craig, $S$ Pathare

What a patient can expect from a consultant psychiatrist. M Shooter

Interventions for people with autism: recent advances. $P$ Howlin

The management of chronic pain. S P Tyrer

Cross-cultural psychiatric assessment. D Bhugra, K Bhui 